Anderson Ribeiro Leite

\title{
Previdência Social: fatores que explicam os resultados
}

\section{Dissertação de Mestrado}

Dissertação apresentada como requisito parcial para obtenção do título de Mestre pelo Programa de PósGraduação em Administração da PUC-Rio.

Orientador: Prof. Walter Lee Ness Junior

Rio de Janeiro

Setembro de 2007 
Anderson Ribeiro Leite

\section{Previdência Social: fatores que explicam os resultados}

Dissertação apresentada como requisito parcial para obtenção do título de Mestre pelo Programa de PósGraduação em Administração da PUC-Rio. Aprovada pela Comissão Examinadora abaixo assinada.

Prof. Walter Lee Ness Junior

Orientador

PUC-Rio

Prof. Marcelo Cabús KIotzle

PUC-Rio

Prof. Narcisa Maria Gonçalves dos Santos

UERJ

Prof. João Pontes Nogueira

Coordenador Setorial do Centro de Ciências Sociais - PUC-Rio

Rio de Janeiro, 19 de setembro de 2007 
Todos os direitos reservados. É proibida a reprodução total ou parcial do trabalho sem autorização da universidade, do autor e do orientador.

\section{Anderson Ribeiro Leite}

Analista de sistemas da Empresa de Tecnologia e Informações da Previdência Social (DATAPREV), graduado em Administração, com MBA em gestão estratégica de tecnologia da informação pela FGV-RJ. Seus interesses em pesquisa estão relacionados à Previdência Social e à tecnologia da informação.

Ficha Catalográfica

Leite, Anderson Ribeiro

Previdência social: fatores que explicam os resultados / Anderson Ribeiro Leite; orientador: Walter Lee Ness Junior. - 2007

84 f. : il. ; $30 \mathrm{~cm}$

Dissertação (Mestrado em Administração)Pontifícia Universidade Católica do Rio de Janeiro, Rio de Janeiro, 2007.

Inclui bibliografia

1. Administração - Teses. 2. Finanças. 3. Previdência social. 4. Receitas previdenciárias. 5 . Benefícios previdenciários. 6. Séries temporais. 7. Econometria. 8. Regressão. I. Junior Ness, Walter Lee. II. Pontifícia Universidade Católica do Rio de Janeiro. Departamento de Administração. III. Título. 


\section{Agradecimentos}

Ao prof. Walter Ness, pelas orientações precisas.

Ao prof. Marcelo Klotzle, pela ajuda com a econometria.

Aos professores do Mestrado, que me proporcionaram as "lentes" adequadas para observar e compreender melhor as organizações.

A Noélia, Pedro e Marcos, esposa e filhos maravilhosos, pelo apoio, incentivo e compreensão pelas horas dedicadas ao Mestrado.

Aos meus pais (in memorian) e ao tio Ribeiro Netto pela formação, carinho e apoio que tornaram possíveis realizações como esta.

À DATAPREV, pelo apoio através do programa de incentivo à pós-graduação. 


\section{Resumo}

Leite, Anderson Ribeiro; Ness Junior, Walter Lee. Previdência Social: fatores que explicam os resultados. Rio de Janeiro, 2007. 84p. Dissertação de Mestrado - Departamento de Administração, Pontifícia Universidade Católica do Rio de Janeiro.

O objetivo desta pesquisa é identificar um conjunto de fatores que exerce influência no resultado financeiro e nos componentes de receitas e benefícios previdenciários do Regime Geral de Previdência Social (RGPS). Para isso, foi feita uma revisão da literatura especializada à procura de referências aos fatores. De posse da relação de fatores citados pelos especialistas no tema, foram selecionados indicadores para representá-los. Em seguida, foram obtidos os dados constituídos por séries temporais dos indicadores. Esses dados foram submetidos ao método de análise de regressão múltipla aplicada à luz do referencial teórico da econometria de séries temporais. Os resultados confirmam a influência dos fatores demográficos, salário mínimo, rendimentos, trabalho informal e desemprego nas receitas, benefícios e resultado financeiro do RGPS.

\section{Palavras-chave}

Previdência Social; benefícios previdenciários; receitas previdenciárias; fatores; administração; finanças; econometria; séries temporais; regressão. 


\section{Abstract}

Leite, Anderson Ribeiro; Ness Junior, Walter Lee. Social Security: factors that explain the results. Rio de Janeiro, 2007. 84p. MSc. Dissertation Departamento de Administração, Pontifícia Universidade Católica do Rio de Janeiro.

The objective of this study is to identify a set of factors that explains the financial results of the General Regime of Social Security (GRSS) in Brazil, including the components of revenues and benefits. To achieve this objective, specialized literature was consulted and the factors referred were listed. For each factor, one indicator was selected to represent it and the time series of indicators values were obtained. In the next phase, the time series were submitted to the multiple regression analysis method, implemented according to the assumptions of econometrics. The results confirmed the influence of demographic factors, minimum salary, wage, informal work and unemployment on revenues, benefits and the global financial result of the GRSS.

\section{Keywords}

Social Security; benefits; revenues; factors; administration; finance; econometry; time series; regression 


\section{SUMÁRIO}

1 Introdução

2 Problema e metodologia $\quad 14$

2.1. Contexto histórico 14

2.2. Organização dos planos previdenciários 16

2.3. Formulação do Problema 19

2.4. Objetivo 19

2.5. Relevância do estudo 20

2.6. Delimitação do estudo 21

2.7. Metodologia 22

2.8. Limitações do método 23

2.9. Tipo de pesquisa 23

3 Referencial teórico 25

3.1. Análise de séries temporais 25

3.2. Análise de regressão 28

3.3. Análise de regressão aplicada a séries temporais 32

$\begin{array}{ll}4 \text { Variáveis previdenciárias } & 37\end{array}$

4.1. Receitas previdenciárias 37

$\begin{array}{ll}\text { 4.2. Benefícios previdenciários } & 37\end{array}$

4.3. Saldo previdenciário 38

4.4. Evolução das variáveis previdenciárias em relação ao PIB 38

5 Revisão da literatura $\quad 40$

5.1. Modelo proposto para a Social Security Administration 40

5.2. Fatores demográficos 42

5.3. Taxa de desemprego 46

5.4. Inflação 48

5.5. Taxa de juros $\quad 50$

5.6. Trabalho informal $\quad 50$

5.7. Salário mínimo 52 
5.8. Rendimentos $\quad 54$

5.9. Resumo dos fatores e seus efeitos 57

6 Tratamento e análise dos dados 58

6.1. Identificação das variáveis 58

6.2. As séries previdenciárias $\quad 59$

6.3. Verificação de premissas $\quad 61$

6.4. Abordagem combinatória dos processos auto-regressivos 66

6.5. Modelos selecionados para benefícios 69

6.6. Modelos selecionados para receitas $\quad 70$

6.7. Modelos selecionados para o saldo previdenciário 71

7 Conclusões $\quad 73$

7.1. Sugestões para pesquisas futuras 75

8 Referências bibliográficas $\quad 76$

9 Anexos $\quad 81$

9.1. Matriz de dispersão dos dados $\quad 81$

9.2. Séries temporais utilizadas 82 


\section{Lista de tabelas}

Tabela 1 - Censos demográficos e projeções da população 44

Tabela 2 - Valores do salário mínimo 53

Tabela 3 - Fatores referenciados na literatura e indicadores selecionados $\quad 56$

Tabela 4 - Identificação das variáveis $\quad 58$

Tabela 5 - Fatores de ajustamento sazonal das séries previdenciárias $\quad 60$

$\begin{array}{ll}\text { Tabela } 6 \text { - Correlação entre as variáveis } & 63\end{array}$

Tabela 7 - Correlação entre as variáveis independentes $\quad 64$

Tabela 8 - Tolerâncias e fatores de inflação de variância $\quad 64$

Tabela 9 - Índices de condição e proporções de variância 64

Tabela 10 - Testes ADF de estacionariedade das séries (p-values) 66

Tabela 11 - Modelos para benefícios com uma variável independente $\quad 69$

Tabela 12 - Modelo multivariado para benefícios $\quad 70$

Tabela 13 - Modelos para receitas com uma variável independente $\quad 70$

$\begin{array}{ll}\text { Tabela } 14 \text { - Modelo multivariado para receitas } & 71\end{array}$

Tabela 15 - Modelos para saldo com uma variável independente 72

Tabela 16 - Modelo multivariado para o saldo previdenciário 72

$\begin{array}{ll}\text { Tabela } 17 \text { - A literatura e o resultado da análise dos dados } & 74\end{array}$ 


\section{Lista de figuras}

Figura 1 - Gasto previdenciário de países selecionados 20

Figura 2 - Modelo da Previdência Americana 41

Figura 3 - Taxas de Desemprego da PNAD, PED e PME 48

Figura 4 - Distribuição de benefícios emitidos (junho/2005) 53

Figura 5 - Rendimentos segundo a PME $\quad 56$

Figura 6 - Autocorrelação parcial das séries previdenciárias $\quad 59$

Figura 7 - Séries previdenciárias antes e após o ajuste sazonal 61

Figura 8 - Autocorrelação parcial após ajustamento sazonal 61 